\title{
BREAST CANCER AS A CHRONIC ILLNESS: IMPLICATIONS FOR REHABILITATION AND MEDICAL EDUCATION
}

\author{
Loh $\mathrm{SY}^{\prime}$ and Yip $\mathrm{CH}^{2}$ \\ Department of Allied Health Sciences, Faculty of Medicine, University of Malaya, 50603 Kuala Lumpur, Malaysia \\ 2 Department of Surgery, Faculty of Medicine, University of Malaya, 50603 Kuala Lumpur, Malaysia
}

\begin{abstract}
Evidence suggests that breast cancer is taking the form of a chronic illness. This will add on to the present burden of managing chronic diseases in the healthcare delivery system. The burden of breast cancer being a chronic illness, calls for greater efforts to address the many neglected, physical-psycho-social and occupational functioning consequences. Timely efforts are needed to identify and implement interventions that are aim at improving the quality of life of women with breast cancer. At present, research evidence is highlighting that chronic diseases may best be managed using a self-management approach, and best treated by a balance of traditional medical care and the day-to-day practice of self-management skills. This paper presents the perspective of breast cancer as a chronic illness and its implication for rehabilitation and medical education. It is imperative that health professionals be made aware of these survivorship issues through medical education. The goals are to reduce the many disability risks, encourage patient-health provider communication and enhance partnership in care, within a timely, holistic therapeutic program to improve the quality of life of women with breast cancer. (JUMMEC 2006; 9(2): 3-11)
\end{abstract}

KEYWORD: Breast cancer, rehabilitation, medical education, self-management, chronic disease

\section{Introduction}

Worldwide, breast cancer is the second most commonly diagnosed cancer ( 1.15 million) after lung ( 1.35 million) (I). Incidence and mortality rates in breast cancer vary widely from one region of the world to another. Incidence rates are high in most of the developed areas (except for Japan, where it is third after colorectal and stomach cancers), and is modest in Eastern Europe, South America, Southern Africa, and Western Asia, but it is still the most common cancer of women in these geographic regions (I). The variations are attributed to the environmental differences in diet and lifestyle. These incidence rates can be up to five-fold higher in western countries than those reported from the Asian region (2). Age standardized incidence rates in developed countries are around 100/100,000 women with mortality rates of about 25/100,000 (3). The unfavourable trend of an increasing incidence of breast cancer is global, due in part to the increase in risk factors (decreased childbearing and breast-feeding, increased exogenous hormone exposure; and detrimental dietary and lifestyle changes, including obesity and less physical activity) (4). With its high incidence rates and relatively good prognosis (and a reducing mortality rate), breast cancer is the most prevalent cancer in the world today; with an estimated 4.4 million survivors up to five years following diagnosis (compared with just I.4 million survivors - male or female - from lung cancer) $(1,5)$.

In Malaysia, the International Agency for Research in Cancers estimated a crude incidence of about 34.86 per 100,000 population in 2000 (6). Breast cancer in Malaysian women occurs more commonly in younger

\section{Correspondence:}

Loh Siew Yim

Department of Allied Health Sciences

Faculty of Medicine

University of Malaya

50603 Kuala Lumpur, Malaysia

Fax: 603-7967 4766

Email: syloh@um.edu.my 
women, aged between 40-49 years, with many presenting in the advanced stages similar to developing countries like Thailand and Pakistan (7). Despite its significant rise in incidence and a significant rise in long term survivorship, not much importance is being considered for the rehabilitation of women with breast cancer. There are many issues for women to manage, following the diagnosis and treatment for breast cancer. In the curative period, intervention are often too medically-focused, without due consideration to other aspects of functioning. In the survivorship period, follow-up medical appointments are often, narrowly and primarily confined to detection of recurrences (I), neglecting any needs for physical and psychosocial rehabilitation. Clinical manifestations of breast cancer can range from a localised to a metastatic neoplasm, and the treatment options are broad ranged, reflecting the heterogeneity of the disease. Despite many years of interests in evidence-based practice, it was recently highlighted in health services research that one of the most unfortunate, consistent finding is the gap between best practice (as determined by scientific evidence), and that of the actual clinical care. Even developed countries such as the United States had at least $30-40 \%$ of patients who do not receive care according to current scientific evidence (8). Adjustment to breast cancer implies coping and dealing with self-care issues as a result of the more obvious physical complications as well as the less obvious ones such as an altered body image, changes in relationship with partner and children, living with any ongoing side effects, and living with the intrusive thoughts of tumour recurrence, and the uncertainties of the futures. In Australia, only a minority of oncology patients with depressive illnesses are identified by staff and referred appropriately (9), although a study found that as high as $45 \%$ of women with early-stage breast cancer reported clinically significant levels of depression or anxiety (10). Health professionals need to explore their roles on how best to support these social adjustments through the illness trajectory. The traditional medical model of healthcare tends not to acknowledge that the mind and body are connected, prolonging a healthcare system that focus predominantly on curative and on the obvious physical impairments.

Indeed, studies on breast cancer and its rising health burden should be conducted alongside studies on current treatment, with careful consideration of its potential impact on functioning and quality of life, by both clinicians and medical researchers. However, despite an increasingly obvious significant survivorship, clinical research and therapy is slow and not forthcoming. The aim of this paper is to discuss the implication of breast cancer taking a form of chronic illness, for medical education and rehabilitation.

\section{Breast Cancer - An Emerging Chronic Illness}

Despite years of research to find the cause of breast cancer, the aetiology remains largely undetermined till today. What researchers know are merely the risks factors, and what clinicians can inform their patients are merely that they are at a certain level of risk. Scientist have been postulating on the many risk factors. Obesity, a lifestyle factor, is said to be specifically linked to lower risk in pre-menopausal women but the risk increases in post-menopausal women (I I). The highest risk is linked to the BRCA genes and geographical location (12). In short, with an aetiology that remains idiopathic with numerous risk factors to blame, coupled with better treatment contributing to longer survivorship, breast cancer is slowly taking the form of a chronic illness (I3).

Scientific evidence, from the highest level of randomized controlled trials down to expert's opinions, at the lowest, is therefore important. In January 2005, an International Consensus Panel of experts met during the 9th Conference on Primary Therapy of Early Breast Cancer in St. Gallen, Switzerland, to develop a series of guidelines and recommendations for adjuvant systemic treatments in specific patient populations (14). Use of tamoxifen, an antiestrogenic drug, has been the gold standard of treatment with its excellent results on women with oestrogen receptor (ER) positive tumours (I5). However, new evidence suggests that aromatase inhibitors, which hinders the aromatase enzyme catalyzing the final step in oestrogen biosynthesis, have shown equally successful result in the prevention and treatment of breast cancer (16). Table I presents an overview of the survival rate in breast cancer, according to staging. With earlier detection and better treatment, these cancer survival rates are improving and have been reported to improve up to above $50 \%$ a decade ago (17) and the rates are still increasing. Better treatment leads to better prognosis and patients need to manage beyond adjuvant treatment periods, since longer survivorship often bring a myriad of survivorship issues.

Although some believe little can be done to reduce breast cancer risk through primary prevention (I2), chemoprevention has been reported as an effective primary strategy (18). There must be further secondary prevention through screening (self and clinical breast examination and mammography), with rehabilitation continuing even after the curative phase to enable patients to adjust to the numerous survival issues. Thus, self-management skill at managing modifiable risks should now be taught to patients, besides the self-management education to equip them to be a 
Table I. Disease-free and 'BC specific survival' by stage of breast cancer, at five years following optimal management, and suggested frequency of follow-up

\begin{tabular}{lccccc}
\hline Stage & $\begin{array}{c}\text { Disease-free } \\
\text { survival (\%) }\end{array}$ & $\begin{array}{c}\text { Breast cancer } \\
\text { specific survival (\%) }\end{array}$ & \multicolumn{3}{c}{$\begin{array}{c}\text { Frequency of follow-up } \\
\text { (monthly) }\end{array}$} \\
\hline & & & Year I & Years 2-3 & Years 4-5 \\
$\mathrm{DCIS}^{\dagger}$ & $90-95$ & $98-100$ & $3-4$ & 6 & $6-12$ \\
$\mathrm{I}^{\dagger}$ & $80-95$ & $80-98$ & $3-4$ & 6 & $6-12$ \\
$\mathrm{II}^{\dagger}$ & $50-75$ & $50-70$ & 3 & $4-6$ & $6-12$ \\
$\mathrm{III}$ & $50-66(15-35 \ddagger)$ & $30-60(15-40 \ddagger)$ & 3 & $3-6$ & $3-6$ \\
$\mathrm{IV}-$ metastatic & $0-5$ & $5-20$ & 3 & 3 & $3-6$ \\
\hline
\end{tabular}

* Data from Stuart et al, 2006

$\dagger$ Treated with breast conserving technique (Stuart et al, 2006)

Figure I. Yearly risk of recurrence in breast cancer

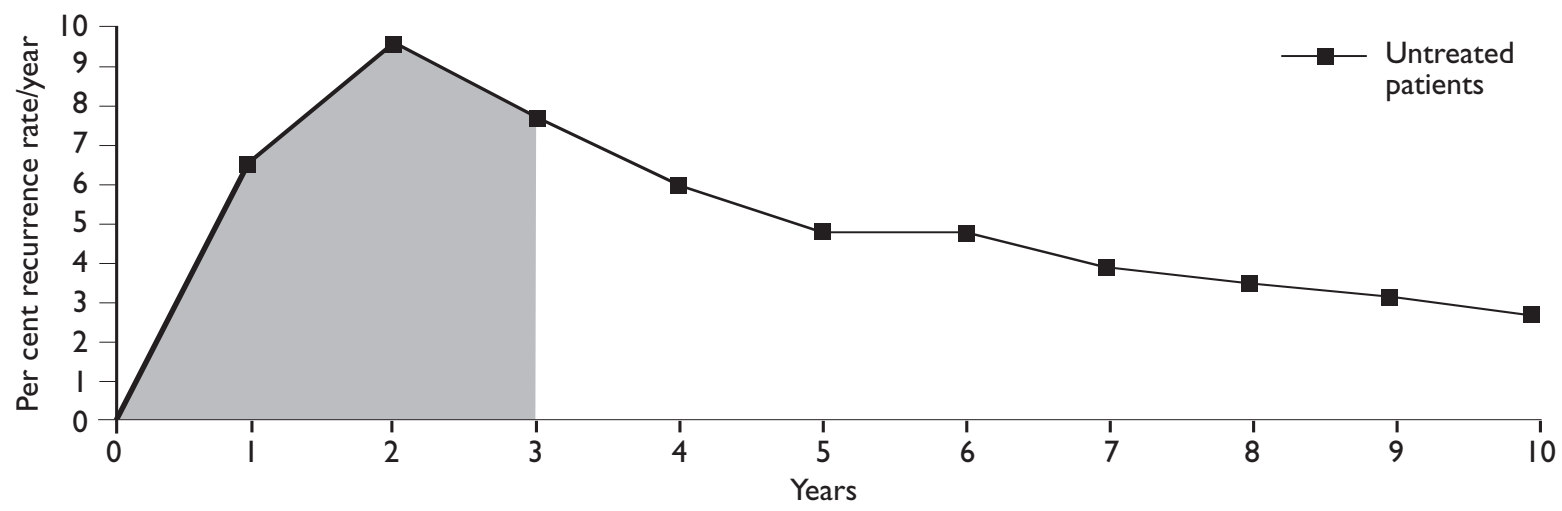

Source: $h t t p: / / w w w . w e b m d . c o m$

partner in managing their breast cancers, in collaboration with their health providers.

Meta-analysis of the risk of breast cancer recurrence in each year during the ten-year period after a diagnosis of early breast cancer in patients who received no adjuvant treatment (treatment following surgery with or without radiation), indicates that risk of recurrence occurs throughout the ten-year period, but is highest in the first three years after a diagnosis, and in the absence of adjuvant follow-up treatment. Risk of recurrence is low after ten years survivorship (Figure I). However, issues of recurrence can affect survivors' quality of life. Quality of life, is an increasingly accepted important outcome criteria in healthcare, and even amongst the early stages, many breast cancer patients often spend the remainder of their life in uncertainties, under the shadow of the possibility of a recurrence in the future.
As an emerging long-term (chronic) illness, breast cancer must be differentiated from acute and terminal illnesses. Acute illnesses are typically short-lived, have no permanent disruption of functioning and cure being almost always certain with predictable outcome. In contrast, terminal illnesses are life threatening with the mostly 'end-of-life' expected outcomes. The difference between acute and chronic illness are substantially different. Chronic illnesses, however, are those with an insidious onset and over a longer course duration. One definition of chronic illness is; "a disease which has one or more of the following characteristics: (a) is permanent, leaves residual disability; (b) is caused by non-reversible pathological alternation; (c) requires special training of the patient for rehabilitation, or may be expected to require a long period of supervision, observation, or care (19). With cure being uncertain, and its challenges over a longer time span, chronic illnesses can have an enduring effect 
on quality of life. Therefore, any factors that affect quality of life can be critical intervention points.

\section{Burden of Breast Cancer as a Chronic Illness}

As the health status of women with breast cancer can be impaired by the side effects of treatment and/or reactions to the cancer diagnosis and experiences, breast cancer like many other chronic illnesses, has an impact on many performance areas in a patient's daily life. Firstly, impairment and disability arising from breast cancer under the various functioning aspects can be wide ranging, and have wide ranging impact on a person's functional status and quality of life. Secondly, the disability in breast cancer to some extent is rather invisible, unlike the visually crippling disability in more physical-form chronic conditions like arthritis and stroke. Thirdly, in terms of duration, although impairment may not be permanent, the impact from living with uncertainty for a long duration is a real burden, and can be taxing on the person's quality of life.

Physical, psychosocial and psychosexual functioning are important sequelae that affects quality of life in women with breast cancer. Evidence suggested that primary treatment have resulted in impairment in emotional functioning, body image, sexual functioning, social-work role $(20,21)$; anxiety, depression, fatigue and insomnia (22); impaired body image and self concept (23); pain, limited range and lymphoedema from surgical treatment (24-26); with an incidence rate of $10 \%$ axillary node dissection, to $24 \%$ dissection with radiation (27). Occupationally, a diagnosis of breast cancer can also hinder women from working for a minimum of a few months to years, and some women may never return to work. The reasons may be wide ranging from fears, myths, physical-psychological disabilities, as well as, to more positive reasons like revaluing life and life priorities. Some women see the diagnosis of breast cancer as a wake-up call and can afford to leave a paid job because, "I realized money is not everything, I want to spend time with my family and do things I enjoyed doing". However, not all women can afford not to work, as another survivor; "the treatment is so costly ... and with two small children to feed, I cannot afford not to work" (28). The implication of being occupationally 'unable' and/or 'disabled' can lead to other complications like lowered income, self-esteem, and reduced social contact with impact on the survivor's quality of life. Another important issue facing women with breast cancer is co-morbidity. Breast cancer is higher in advancing age, with risk of other illnesses (i.e., osteoporosis, heart disease and hypertension) setting in. Factors like complicated menopausal symptoms may further worsen the cancer experience. All these factors invariably affect the mental health and overall quality of life of these patients.

\section{Impact on Physical Functioning Issues}

Evidence suggests breast cancer patients suffered impairments of the upper limb, even at one year after operation and many experiencing limited activities of daily living with negative impact on quality of life. Lymphoedema of the upper limb can occur even 2030 years after axillary treatment (29), and it causes much mental distress. Estimates on the risk of severe lymphoedema can range from $6 \%$ with one treatment modality up to $30 \%$ with the combination of axillary clearance and radiotherapy. The persistence of a distorted body image, made worse with visible lymphoedema limbs can aggravate the difficulty to resolve the initial shock and denial, and/or the later adjustment phases. It is expected that with better and earlier screening, stages are detected earlier with less aggressive treatment and thus, lower complications, but more research is due in this area. One study found that two strong predictors of survivors' quality of life are arm-dysfunction and doctor-patient communication (30). These two aspects have been observed to be grossly lacking in our healthcare. Both deficits need to be highlighted in the medical education of the undergraduate as well as the postgraduate. Table 2 highlights many other common side-effects of breast cancer treatment can have an impact on the quality of life. An awareness of these consequences can help the health professionals in supporting their patients (29).

\section{Impact on Psycho-sexual Functioning Issues}

Breast cancer can have a debilitating impact on a woman's feelings of well-being, wholeness, sexuality and attractiveness to varying degree, since the breasts has been regarded as a symbol of femininity and beauty. Thus, a woman's choice of treatment can be influenced by her age, her belief and cultural background, religion and faith, as well as her hopes and fears. A single women who had a mastectomy shared, "society sees women as having two breasts ... and I felt I have lost my femininity" (28). Younger ones appear to have more difficulties, especially suitor-marriagechildbearing issues or societal-expected issues. However, guidelines stipulating age, as a criteria for convenience or based on popular beliefs, rather than per medical evidence is an issue for some women. A survivor in her 60s was angry that she was never told she could opt for breast reconstruction, and was 
Table 2. Common physical side-effects from cancer treatment

\section{Surgery}

- 'Pulling' over the scar/pain/discomfort

- Scar contracture

- Paraesthesia in the axilla and medial upper arm (due to an axillary clearance)

- Lymphoedema

- Physical imbalance and difficulties with neck pain due to breast tissue loss (for those with big breasts)

- Intermittent jabbing neurological breast pains

- Intermittent pain in the upper arm on the side of an axillary clearance (may settles over 3-6 months)

\section{Chemotherapy}

- Tiredness/fatigue

- Hair loss

- Bitter taste in mouth (may clear few weeks after chemotherapy)

- Peripheral neuropathy may persist

\section{Radiotherapy}

- Breast oedema and tenderness

- Hyperpigmentation in the first year

- Later, an increased density of the breast tissue

- Small decrease in the size of the residual breast

Hormonal therapy (tamoxifen)

- Hot flushes

- Tender breasts

- Gastrointestinal upset

- Vaginal dryness and discharge

- Decreased libido

- Abnormal vaginal bleeding

\section{Hormonal therapy}

(Aromatase inhibitors or $\mathrm{Al}$ )

- Hot flushes

- Musculoskeletal pain (may have to stop Al)

- Vaginal dryness

- Osteoporosis

Adapted from Stuart et al, 2006

furious when told that the offer was only for women below 40 years old (28). Lack of plastic surgeons to perform the job should be addressed and immediate action taken to overcome the shortage, rather than addressing the issue at the expense of the patients.

In a multicultural society, ethnicity as a barrier to treatment adherence must also be considered. A woman shared about her Muslim-convert sister who had vehemently refused mastectomy because of the fears that her husband may look for another wife. The decision has cost her life, and her survivor sister justifies, "I would rather have one breast and live, than to have two breasts and die" (28). This apt message has been adopted as a key message for women attending the four week SAMA (staying abreast, moving ahead) self-management program scheduled for Malaysian women. [The clinical trial program is currently conducted at the University of Malaya Medical Centre Kuala Lumpur]. Although she felt that she was luckier and more rational to choose life over a breast, it cannot be denied that losing a breast is a loss, there is a process of grieving over any lost and the impact would vary from one to another. Unfounded beliefs and myths (highlighted in several focus group with women with breast cancer) (28), and the fear of recurrence also interfere with intimacy. One example is the myth that toxicity of chemotherapy and cancer cells can spread through intimacy, and that sexual excitement can cause recurrences. These concerns on sexuality, attractiveness and beliefs aggravating a woman's sexual problems, are part and parcel of the psycho-sexual issues with implications on their occupational life roles. Thus, women need extra support and time to develop openness, and acceptance in overcoming the changes due to body image, fear of rejection, doubt of attractiveness, low self-esteem and mental distress.

\section{Impact of Breast Cancer on Psychosocial Functioning}

The nature of the breast cancer illness, its severity, the treatment and side-effects; coupled with many other personal-environmental factors like personality, finances, lifestyle prior to the illness and the access and level of social support, impact the ability to 'journey' and adjust to the realities of this long-term condition. Mental distress can occur in response to the uncertainty of recurrence, leading to depression and complicated grief. All these can be further aggravated by any prevailing cultural-religious myths, such as breast cancer being caused by bad 'karma' or a punishment for a past misdeed. Like any major illness, an expected search for the 'why' questions, or the need to find solace and hope occurs at a time when nothing else makes sense, which makes support so crucial.

A cultural stigma of a cancer diagnosis may also complicate patients' social functioning and roles. The consequences of the patients' own reactions, as well as others' reactions, can lead to increase in withdrawal and isolation, sometimes made worst by family who 
are profoundly affected, and unable to cope and/or unsure of how to react; and may need professional support. Women and their family may also need assurance that breast cancer is not a punishment from God for their bad deeds. One survivor shared on how she was ostracised by her in-laws who continuously injected the idea that she was receiving her dues for her past misdeeds. A belief that they are not alone in the challenges that they face can certainly add quality to life. They need the message that breast cancer is highly prevalent and can affect anyone, good and noble women, as well as even men.

Further losses come in the form of having to relinquish roles and responsibilities, because of myths like stress causes breast cancer. One survivor shared that her overly protective family barred her from doing any housework and she was told to just sit around and not to work to avoid stress. However, staying away from work causes one to lose the support system, as well as the financial security and become a potential burden to loved ones. These also may take a toll on one's self-esteem, self-worth and self-image; leading to more shame and possibly resentment and anger. Such myths must be nipped in the bud so that whatever decision women take are choices based on informed decisions. This is because the consequences of abandoning functional roles, leads to a feeling of dependency, and the emotions around the loss of status and control can threaten the once - healthy, capable and functioning individual.

The traditional medical model of healthcare tends not to acknowledge that the mind and body are connected, prolonging a healthcare system that focus predominantly on curative and on the obvious physical impairments. This care delivery is rather limiting and not in line with the progression of the development of the breast cancer disease. The neglects on the nonphysical impairment need to be redressed, with an acknowledgement that a lowered emotional-distress, and social participation can greatly impact the body in a positive way. Intervention must target at both the seen and on the 'unseen' impairments in broader life scope. For example, cognitions or thoughts must be deliberately considered, as potent determinants of how patients feel and they influence the choices patients make. A diagnosis of cancer, often trigger people's inner struggle around their faith, and at times, bring out self-imposed blame and punishment for having the condition. When a belief or thought is based on a premise that is distorted and self-defeating, an increase in distress may be experienced unnecessarily. Therefore, cognitive-restructuring coping skills must be taught to refute negative automatic thoughts or myths that underline patients' anxiety or depression.
Such cognitive reappraisal enables them to focus on the positives, identify personal strengths and enhance their self-efficacy in coping and managing the condition. During this crisis period, the empathetic ability and/or training of the health professionals to render support can enable patients to reclaim the meaning of life behind the illness and/or assert their gratitude for their life. Health professional must be alerted on these extensive, at times, tremendous impact, and despair brought about by a cancer diagnosis. The capability of health professionals to respond sensitively to patients and their families is increasingly being seen as fundamental in this partnership in cancer care. Self-management of emotions, in collaboration with relevant health professionals, is crucial and it can improve the goal setting and problem solving skills for self-managing the condition more effectively.

\section{The Crux of Managing Breast Cancer as a Long-term IIIness}

This review raises two important questions: (a) are there unique issues for women with a longer term survivorship, and (b) should women with breast cancer, as an emerging chronic illness, be treated differently from those yesteryears? The answer to the first question would depend on more research findings. The answer to question two is a strong definite 'yes'. In fact, breast cancer, once a short term potentially fatal illness, has now added to the burden of chronic illnesses as rising incidence rates and better treatments have contributed to more cases and longer survivorship. As the burden of chronic illness continues to rise and takes over as the number one source of healthcare expenditure worldwide, it is imperative to identify efforts and implement timely, culturally sensitive, and long-term, cost-efficient interventions for women with breast cancer.

Rehabilitation interventions for long-term conditions must now focus proactively on integration of medicalemotional-role management with a primary prevention emphasis on promoting healthy lifestyle; as well as, on secondary prevention defining risk reduction habits to keep cancer at bay, and to enhance participation and quality of life. Patients must be alerted on the need to make changes in behaviour and lifestyle in order to promote risk reduction habits. This is so pertinent in breast cancer as getting patients to re-focus on health (rather than looking for cure) makes much more sense as survivorship increase dramatically with better treatment. Our rehabilitation aim must now extend beyond reducing present disabilities (visible and invisible ones) towards more concerted efforts on facilitating im- 
Figure 2. Some basic accessory aids for enhancing body image, posture and managing lymphoedema

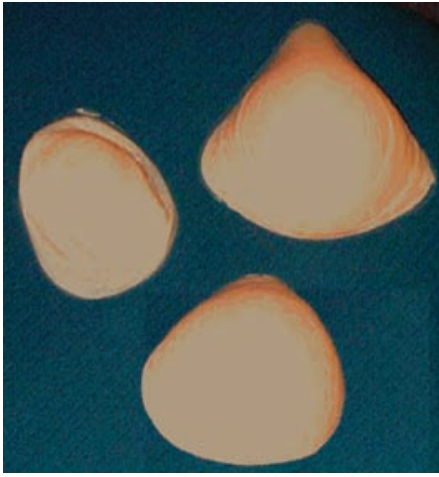

Silicone prosthesis

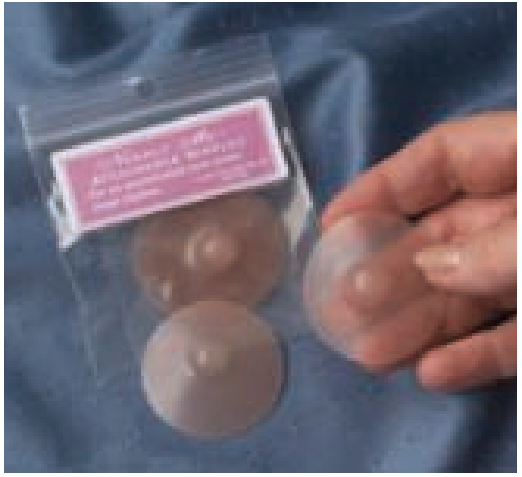

Attachable nipple

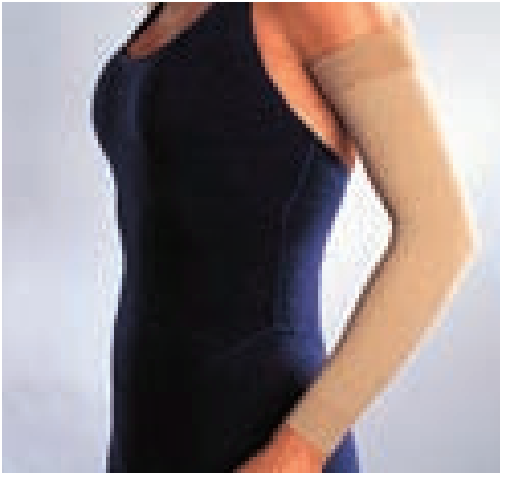

Pressure garment provement in participation and quality of life. These may require aids and adaptations, and prosthesis to adjust to impairments such as the commonly available aids in Figure 2 which is making an entry, albeit a slow one, in our therapy settings.

\section{The Essence of Self-management Interventions}

Along the concept of self-care, is a current interest (in the ongoing conceptualization) of 'self-management', which is not about patients going alone managing by themselves. The essence of self-management is about collaborative care with health professionals. Von Korff and colleagues ( $3 \mathrm{I}$ ) assert that chronic disease is best treated by a balance of traditional medical care and the day-to-day practice of self-management skills; both can be enhanced by effective collaboration from the patients, their families and healthcare providers. Collaborative management is said to occur when patients and care providers have shared goals, a sustained working relationship, mutual understanding of role and responsibilities, and requisite skills for carrying out their roles (3I). This is important since the impact of breast cancer is extensive and drawing from both experts (patient as expert in day-to-day management, and the healthcare providers as experts in the medical care) is the best management approach to reduce hospitalization cost and improve healthcare delivery. Self-management program supports patients to live the best possible quality of life with their chronic condition. Under this broad category of interventions, some may include informational and educational strategies, cognitive and behavioural skills, vicarious learning and peer support methods that focus on changing specific thoughts and healthy habits. Training to prepare patients to be informed, and activated may include problem solving skills, resource utilization, relaxation training and stress-coping train- ing. The idea is rooted on the chronic care model where optimal chronic care is achieved when a prepared, proactive practice team work collaboratively with an informed, activated patient (3I). A partnership approach to enable patients to self-manage is an integral collaboration for quality primary care.

\section{Implications for Medical Education and Rehabilitation}

The recognition that breast cancer is gradually taking a form of a long-term illness requires a cognitive shift in understanding its unique implications. It differs from that of an acute illness or a terminal illness and this requires a paradigm shift in our management of breast cancer. As a long-term illness, breast cancer is comprehensive in its effects, as well as being tremendously varied from one person to another. The implication is more far ranging than merely treating the illness and symptoms as studied in many chronic illnesses. Thus, medical care for chronic illness is rarely effective in the absence of adequate self-care. Medical care with selfmanagement should be actively encouraged and promoted, and health professionals must be willing to adopt a less authoritarian approach towards more collaborative care. The attitude of 'I know best' may more likely interfere rather than complement the management of an increasing chronic condition and an increasingly affluent society. Self-management and partnership is the best way to manage a condition that can lasts for years or decades and its success requires a dire change, not just in the roles of our patients but in the knowledge, skills and attitudes of our health professionals.

Adjustment to breast cancer implies coping and dealing with self-care issues as a result of the more obvious physical complications as well as the less 
obvious ones such as an altered body image, changes in relationship with partner and children, living with any ongoing side-effects, and the fear of tumour recurrence, and the uncertainties of the futures. Occupational therapists working with people with chronic illnesses spend considerable time rehabilitating them to improve their independent functioning in self-care and the overall activities of daily living. Each person's illness is very unique and can range from mild to severe limitation in participation and quality of life. Instead of resuming or returning to a previous lifestyle and functioning (as in an acute illness), or struggling with life (terminal illness), people with breast cancer are now faced with having to adjust to long term, and very likely, lifelong symptoms and limitations. The constant adjustment needed along the way requires ongoing support. Recently in Malaysia, two cases of death were reported; (a) the late first lady who was battling with a recurrence and (b) a 55-year old survivor of ten years from Alor Star, Kedah (32). Both were highlighted in the media. The contrast was the former fought till the end; whilst the latter, a mother of two boys, after being ten years of being disease-free, opted to terminate her life. This case should trigger a revisit on the clinical practice guidelines for management of breast cancer. Appropriate therapeutic intervention can reduce the high levels of emotional distress experienced by many women with breast cancer. Having an awareness of these medical and survivorship issues allows the health professional to provide important support to both the patient and her family. The role of rehabilitation after the active curative treatment must be initiated for breast cancer, to optimize quality of life. Optimizing quality of life is not only an important outcome in itself, but it is also associated with longer survival and lower levels of depression in breast cancer (33).

\section{Conclusion}

Ideas improve the healthcare delivery, but not till they are transformed into feelings (and sufficient enough to trigger action). Quality of life is often linked to what patients can do (the visible), less on how they feel and even less on what they think. Yet the reverse may be equally, if not more significant, in breast cancer. Thus, the recognition that healthy living is also important in such long-term conditions, must also be balanced with an awareness that it depends on positive attitude and an awareness on how to self-manage living with breast cancer successfully. Attempting to self-manage the actual illness on a daily basis, and the profound nature of the changing emotional consequences can lead to feelings of helplessness and hopelessness. Living with hope, when cure is so fleeting, is an important element that must be emphasized in rehabilitation. It brings hope and a belief that they can live through another day, in spite of experiencing the disease and the uncertainties of a recurrence. The aim of rehabilitation being to promote global physical and psychosocial adjustment by targeting at all modifiable levels, i.e., strengthening individual coping resources through psychotherapy, improving quantity and quality of familial and social support, and restoring optimal physical functioning (34). Managing health, emotions and roles as well as managing risk-reduction, thus, play a crucial part in the overall management of breast cancer, as in many chronic illnesses. Medical care with self-management should be actively encouraged and promoted, and health professionals must be willing to adopt a less authoritarian approach towards more collaborative care. Self-management and partnership is the best way to manage a condition that can lasts for years or decades and its success requires a dire change in the roles of patients as well as in the health professionals.

\section{Acknowledgement}

The authors wished to thank Prof Low Wah Yun for co-facilitating, and Ms Tan Wah Chah, Ms Peggy Lim and $\mathrm{Dr}$ Selina Khoo for taking turns to help out with the focus groups interviews held between JuneAugust 2005. A report of the focus group qualitative study will appear in APJPH (2007: Vol. 19, No. 3). The SAMA clinical trial (4-week program) is currently recruiting patients for the clinical trial.

\section{References}

I. Rojas M,Telaro E, Russo A, et al. Follow-up strategies for women treated for early breast cancer. Cochrane Database Syst Rev. 2000; 4 (CD00 I768).

2. Lacey J, Devesa S, Brinton L. Recent trends in breast cancer incidence and mortality. Environ Mol Mutagen 2002; 39: 82-88.

3. Greenlee R, Murray T, Bolden S, et al. Cancer Statistics. CA Cancer J Clin 2000; 50: 7-33.

4. Parkin DM, Fernandez LMG. Use of statistics to assess the global burden of breast cancer. Breast J. 2006; 12 (Suppl I): S70-S80.

5. Parkin DM, Bray F, Ferlay J, et al. Global Cancer Statistics, 2002. CA Cancer J Clin 2005; 55(2): 74- 108.

6. Ferlay J, Bray F, Pisani P, et al. Globacan 2000: Cancer Incidence, Mortality and Prevalence Worldwide. Lyon; 200I. Report No.: Version I.0 No. 5. 
7. Hisham AN, Yip $\mathrm{CH}$. Overview of breast cancer in Malaysian women: a problem with late diagnosis. Asian J Surg. 2004; 27, 2: I30-3(2): I30-I33.

8. Grol R, Wensing M. What drives change? Barriers to and incentives for achieving evidence-based practice. Med J Aust 2004; 180 (6 Suppl): S57-S60.

9. Ford S, Fallowfield L, Lewis S. Can oncologists detect distress in their out-patients and how satisfied are they with their performance during bad news consultations? $\mathrm{Br}$ J Cancer. 1994; 70: 767-770.

10. Kissane D, Clarke D, Ikin J, et al. Psychological morbidity and quality of life in Australian women with early-stage breast cancer:A cross-sectional survey. Med J Aust 1998; 169(4): 192-6.

I I. Kuller L. The etiology of breast cancer - from epidemiology to prevention. Public Health Rev 1995; 23: I57-2I 3.

12. Kelsey J, Bernstein L. Epidemiology and prevention of breast cancer. Annu Rev Public Health 1996; 17: 47-67.

13. Fallowfield L. Evolution of breast cancer treatments: current options and quality-of-life considerations. Eur J Oncol Nurs 2004; 8S, S75-S82.

14. Goldhirsch A, Glick JH, Gelber RD, et al. Meeting Highlights: International Expert Consensus on the Primary Therapy of Early Breast Cancer 2005. Ann Oncol 2005; I6: I569-I583.

15. Jordan V. Estrogens and antiestrogens. In: Holland JF FE, Bast RC, Kufe DW, Morton DL, Weichselbaum RR Eds. Cancer Medicine. Philadelphia: Lee and Febiger; 1993. pP 857-865.

16. Campos S. Aromatase inhibitors for breast cancer in post-menopausal women. Oncologist 2004; 9: 126-136.

17. American Cancer Society. Breast cancer facts and figures, 2005-2006. Atlanta, Georgia: ACS; 2005.

18. Kinsinger L, Harris R, Lewis C, et al. Chemoprevention of breast cancer - systematic review. Rockville, Maryland: RTI/University of North Carolina; 2002. http://www.ncbi. nlm.nih.gov/books/bv.fcgi?rid=hstat3.chapter. 2527 . (accessed 20 Jan 2006).

19. DHA. Delaware Healthcare Association Glossary of Health Care Terms and Acronyms. In: Dover D, Ed. Health Care Professional Resources. Dover, Delaware: Delaware Healthcare Association; 1998.

20. Irvine D, Brown B, Crooks D, et al. Psychosocial adjustment in women with breast cancer. Cancer 1991; 67(4): 1097-II7.
21. Irvine D. A critical review and meta-analysis of the literature investigating psychosocial adjustment in breast cancer. Ottawa: Health Canada: 1996.

22. Shimozuma K, Ganz P, Petersen L, et al. Quality of life in the first year after breast cancer surgery: rehabilitation needs and patterns of recovery. Breast Cancer Res Treat 1999; 56: 45-57.

23. Rowland JH, Desmond KA, Meyerowitz BE, et al. Role of breast reconstructive surgery in physical and emotional outcomes among breast cancer survivors. J Natl Cancer Inst 2000; 92(I7): | 1422-I429.

24. Tasmuth T, Von Smitten K, Kalso E. Pain and other symptoms during the first year after radical and conservative surgery for breast cancer. Br J Cancer 1996; 74: 2024-203I.

25. Knobf M. Symptoms and rehabilitation needs of patients with early stage breast cancer during primary therapy. Cancer 1990; I5(66): I392-I40I.

26. Knobf MT, Sun Y. A longitudinal study of symptoms and self-care activities in women treated with primary radiotherapy for breast cancer. Cancer Nurs. 2005; 28(3): 210.

27. Johansson K, Ingvar C, Albertsson M, et al. Arm lymphoedema, shoulder mobility and muscle strength after breast cancer treatment. A prospective 2-year study. Adv Physiotherapy 200I; 3: 55-66.

28. Loh SY, Packer T, Yip CH, et al. Perceived barriers to self-management in Malaysian women. Asia Pac J Public Health 2007; 19(3). (In press)

29. Stuart K, Brennan B, French J, et al. Life after breast cancer. Aust Fam Physician 35(4), April 2006; 35: 177 258.

30. Engel J, Kerr J, Schlesinger-raab A, et al. Predictors of quality of life of breast cancer patients. Acta Oncologica 2003; 42(7): 710-718.

3I. Von Korff M, Gruman J, Schaefer J, et al. Collaborative management of chronic illness. Ann Inter Med. 1997; 127: 1097-I 102.

32. Embun M. "Cancer Mum - I cut my wrist". The Star Newspaper (Nation) 2005 20th Oct; Sect. 23.

33. Coates A, Hurny C, Peterson $\mathrm{H}$, et al. Quality-of-life scores predict outcomes in metastatic but not early breast cancer. J Clin Oncol 2000; 18(22): 3768-74.

34. Ronson A, Body J. Psychosocial rehabilitation of cancer patients after curative therapy. Support Care Cancer 2002; 10(4): 28I-29I. 